ReBEn, 34 : 153-163, 1981

\title{
MODELAGEM DE COMPORTAMENTO DA GESTANTE TABAGISTA - CUIDADO PREVENTIVO DA ENFERMAGEM OBSTÉTRICA *
}

\author{
Edith de Figueiredo Domingues **
}

\begin{tabular}{cc} 
& ReBEn/04 \\
\hline $\begin{array}{c}\text { DOMINGUES, E.F. - Modelagem de Comportamento da Gestante Tabagista - Cuidado } \\
\text { Preventivo da Enfermagem Obstétrica. Rev. Bras. Enf.; DF, 34 : 153-163, 1981. }\end{array}$ \\
\hline
\end{tabular}

\section{1 - INTRODUÇÃO}

A Enfermagem Obstétrica como elemento integrante do sistema de atendimento à saúde busca encontrar, gradativamente, novos e melhores meios para prover cuidado à grávida ameaçada, nas várias situaçôes, pelas modificaçōes sistêmicas gerais e locais, que alteram a sua integridade psicossomática.

É com relativa freqüência que agentes adversos surgem em qualquer fase evolutiva, daí o mau prognóstico, levando inclusive a perda fetal.

Alguns fatores são absolutamente imprevisiveis; todava, outros são conhecidamente nefastos e, sempre que presentes, ocasionam eventual perigo para o bem-estar fetal. $O$ hábito tabagista associado à gravidez tem sido apontado como fator de intoxicação fetal.
Faz parte da preocupação constante da Enfermagem Obstétrica contribuir para divulgação e conscientização dos perigos a que a fumante grávida fica exposta, e da transmissão concomitante dos riscos de morbi-mortalidade do concepto.

Objetivando a reflexão sobre esta problemática, sentimos a necessidade de abordar o assunto na pretensão de suscitar debates e aprofundamento de estudo. Pesquisando-se e estudando-se um caso, mais perto estaremos da sua solução.

Para as novas descobertas, precisase recorrer a bases teóricas, que fundamentem especificamente a execução da prática, através do conhecimento multidisciplinar. A Enfermagem requer investigaçōes constantes, para dispor de um "Know How" (corpo de conhecimento próprio), que a conduza mais rapidamente aos seus objetivos.

* Trabalho apresentado no XXXII Congresso de Enfermagem, Brasilia - Distrito Federal.

* Prof. Adjunto do Dept. ${ }^{\circ}$ de Enfermagem Comunitária da E.E.UFBa. Enfermeira da Secretaria de Saúde do Estado da Bahia - Setor materno Infantil. 
DOMINGUES, E.F. - Modelagem de Comportamento da Gestante Tabagista - Cuidado Preventivo da Enfermagem Obstétrica. Rev. Bras. Enf.; DF, 34 : 153-163, 1981.

A procura de respostas, para uma melhor atuação junto à gestante tabagista, iniciamos a nossa pesquisa no sentido de investigar que problemas e necessidades deveriam ser identificados nas gestantes tabagistas, sob o nosso cuidado. Assim, nos sentimos gratificados em poder apresentar a tentativa deste nosso trabalho como tema livre do XXXII Congresso Brasileiro de Enfermagem que ora se realiza.

Representa um esforço no sentido de contribuir com subsídios para uma assistência preventiva, realizada assistemática e informalmente, através de um trabalho planejado e com objetivos definidos.

\section{2 - OBJETIVOS}

\section{$2.1-$ Geral}

Efetivar um processo sistemático operacional de orientação para a gestante tabagista, associado à assistência específica de Enfermagem Obstétrica, visando promover a sua modelagem comportamental, a fim de reduzir os efeitos nocivos do fumo para a unidade mãe-filho.

\section{$2.2-$ Especificos}

2.2.1 - Contribuir para redução de partos prematuros e baixo peso fetal.

2.2.2 - Favorecer para maior produtividade, pelo ingresso de novas e mais hígidas geraçōes.

2.2.3 - Identificar a predisposição da paciente para a ação desejada e fortalecer suas reaçōes e atitudes positivas, até conduzi-la a reforços naturais, que facilitam a modelagem comportamental e adequam mais rapidamente suas açōes à nova situação.

2.2.4 - Orientar a gestante tabagista na sua privaticidade a incorpora ativa, consciente e efetivamente o de- sejo de promoção da saúde do concepio, pelo seu autocuidado.

2.2.5 - Valorizar a interação tanto do aspecto físico, quanto do psicossocial de cada PASSO, para facilitar o avanço progressivo da modelagem comportamental da paciente, no plano terapêutico, como resposta às suas necessidades.

\section{3 - CONCEITOS E PRINCIPIOS}

Assistir em enfermagem é fazer pelo ser humano aquilo que ele não pode fazer por si mesmo; ajudar ou auxiliar quando parcialmente impossibilitado de se autocuidar; orientar ou ensinar, supervisionar e encaminhar, a cutros profissionais. ${ }^{4}$

Decorrente do nosso posicionamento profissional com habilidades inerentes à condição de enfermeiro obstetra, advêm-nos o direito e responsabilidade de identificar os problemas e dificuldades das pacientes no ciclo grávido-puerperal, e de, junto com elas, formular planos assistenciais. Fundamentados nas suas necessidades básicas, expectativas, percepçōes, antecedentes pessoais e obstétricos, fazemos a estimativa diagnóstica das necessidades afetadas, da capacidade de atender a estas necessidades alteradas, o grau de dependência do atendimento, além de avaliarmos as mudanças sucessivas ocorridas durante a evolução do processo.

No contexto do dia-a-dia, torna-se possível, concomitante ao desempenho do nosso papel instrumental junto às açōes preventivas, contribuir para a modelagem do comportamento da gestante tabagista. Tentamos a redução ou abolição do vício, colocando-a sob enfoques sócio-psicológicos que obedecem a uma seqüência gradativa de interação, participação e açōes positivas.

Para efeito de complementação, vejamos alguns conceitos básicos que nos conduziram à ação:

INTER - Prefixo que significa entre, no meio de. 
DOMINGUES, E.F. - Modelagem de Comportamento da Gestante Tabagista - Cuidado Preventivo da Enfermagem Obstétrica. Rev. Bras. Enf.; DF, 34 : 153-163, 1981.

AÇAO - Movimento ou efeito mecânico de estímulos ou excitaçōes nervosas.

INTERAÇÃO - Combinaçāo de vários elementos ou fatores com determinada finalidade.

PARTICIPAÇÃO - Ato de se associar pelo pensamento ou sentimento.

COMPORTAMENTO - E o modo de agir diante de situaçōes (muito importante na análise psicológica).

MOTIVAÇÃO - Condiçāo interna relativamente duradoura que leva 0 indivíduo ou que o predispōe a persistir num comportamento orientado para um objetivo, possibilitando a transformação ou a permanência da situaçāo. Essa vontade interior que leva o indivíduo à açāo se faz por meio de incentivos.

GENERALIZAÇAOO - Execuçāo de um comportamento aprendido em uma nova situaçāo que se pode generalizar para outras situaçōes.

Entendendo-se "prática" como um processo de trabalho e como tal um processo de transformaçōes e de relaçōes sociais, a prática profissional do enfermeiro obstetra exige reflexōes, impostas numa época em que se tornam necessários, nāo apenas as mudanças nas direções, mas também estudos críticos dos seus princípios básicos do seu valor, do seu alcance e de suas relaçōes com a sociedade. essa prática comporta uma variedade de análises.

Dois aspectos devem ser considerados na interaçāo enfermeiro-paciente. Este traz consigo sua bagagem cultural (costumes, valores, gostos, atitudes, conhecimentos, tabus etc.). O enfermeiro possui, além de sua cultura a sua formação profissional e sua experiência pessoal, para contribuir na reestruturaçāo comportamental da paciente. Toda atividade se baseia nos princípios que regem as atitudes e reaçōes do indivíduo, face ao meio social em que vive, com a utillização de técnicas ade- quadas para tornar mais eficaz a atuação.

\section{4 - IMPLICAÇŌES DA EQUIPE PRE- NATALISTA}

Esforços conjugados num trabalho de equipe serāo utilizados no empenho de dar maior amplitude e continuidade ao combate deste vício que se alastra pelo mundo como uma praga social. Uma contribuiçāo consciente e coletiva é ponto importante e vital condiçāo, para a interaçāo global nos planos individual, social, ambiental, além de significativa contribuiçāo para a paciente modificar seu comportamento e de superar a limitaçāo sem frustraçāo.

E óbvio que também precisamos atuar pelo exemplo; os nossos ensinamentos devem ser coerentes com nossas açōes. mar no recinto de trabalho.

Se esta consciência profissional nāo for percebida, sentida, assimilada significativamente por cada um de per sí, tudo continuará como está. Os esforços isolados e grupais encontrarāo eco e melhores margens para soluçōes dos problemas existentes, associando-se às reais necessidades, com as exigências exequíveis.

\section{5 - CONCEPÇAO DA GESTANTE COMO PESSOA HUMANA}

É dificil definir a pessoa humana sem levar em consideraçāo as suas condiçōes sócio-econômicas e ambientais ? $\mathrm{O}$ que podemos caracterízar é a INTERAÇAO HUMANA; e o indivíduo é o ponto em que as interaçōes se apresentam sob a forma de qualidades humanas.

Humanidade é uma qualidade de reconhecimento ou interaçāo.

Para que o ser humano se realize é necessário uma sociedade. Como esta sofre contínua mudança, as interaçōes estāo sujeitas a mudar. O ser humano 
DOMINGUES, E.F. - Modelagem de Comportamento da Gestante Tabagista - Cuidado Preventivo da Enfermagem Obstétrica. Rev. Bras. Enf.; DF, 34 : 153-163, 1981.

por sua vez, tem que ser capaz também de mudar, quando há incentivos que o levam à motivação. Dentro desse espírito consideramos que as grávidas tabagistas podem todavia modificar o seu comportamento, tornando-se acessíveis às exigências de uma nova situação, desde quando, bem conduzidas e orientadas adequadamente, com dosagens convenientes de satisfaçōes permitidas e as limitaçōes impostas pela nova idéia. O nosso incentivo consiste em tornar a gestante cheia de otimismo. esperança e sobretudo consciente, para. evitar os malefícios que o fumo pode causar ao concepto.

O movimento de INTEGRAÇAOO deve ser de dentro para fora para não constituir um passo perigoso, resultante da rigidez de princípios que se impōe 2. Outro perigo está em se pôr toda ênfase na ação, sem se preocupar com a mentalização ou tomada de consciência que corresponde a uma integração superior.

De acordo com a proposição psicanalítica ${ }^{14}$, as proibiçōes se transformam em sobrevivência histórica, incapaz de se adaptar às mudanças exteriores. Assim sendo, deve-se considerar na modelagem comportamental da tabagista que as atitudes impeditivas drásticas podem surtir efeitos contraditórios.

Qualquer mensagem, para ser melhor acolhida, exige habilidade para romper o invólucro da descrença, ao medo e do comodismo, gerando um marco de sabedoria e instrução.

Sāo características essenciais de uma INTERAÇAO: ser humana, espontânea, pessoal 13 .

Todas as vantagens materiais que se possam oferecer às pessoas não substituem aquelas necessidades que estão no âmago de todos nós: queremos ser ouvidos, reconhecidos, cuidados, orientados, pertencer a um grupo e assumir responsabilidades de acordo com a nossa habilidade e boa vontade para assumilas.
A problemática gravidez-tabagismo exige sobretudo orientação correta e oportuna. ORIENTAÇAO no sentido de um processo de colocar as gestantes em contato com suas compulsōes, para desta forma poderem manejá-las, serem conscientemente livres e usarem esta liberdade construtivamente em seu próprio benefício e da espécie humana. Entrando em contato com suas partes negativas elas poderão ficar atentas e usarem todas as suas potencialidades de maneira a não as desperdiçar.

$\mathrm{Na}$ opinião de Rachel Dunaway Cox ${ }^{6}$, a tarefa de orientador é muito complexa e variada. Precisa ser um aconselhador educacional e vocacional, um assistente social, um professor, um organizador, um animador, um orador e niesmo um "relaçōes públicas".

Ac mesmo tempo ele precisa das habilidades de um psicólogo, noçōes de um médico e alguns "insights" (perspicácia) de psiquiatra.

\section{6 - TEORIA ANALITICA-CLASSICA DA INTERAÇAO}

Esta teoria do desenvolvimento humano é dinâmica na medida que explica as interaçōes mútuas do próprio indivíduo, e deste com o ambiente. Abrange 3 formulaçōes $i$ :

- ESTRUTURAL - É a formulação que define a atividade mental em termos de interação entre suas partes. Sob o ponto de vista estrutural há 3 partes: ego, superego e id.

- TOPOGRAFICA - A formulação que localiza a atividade mental em algum lugar do aparelho mental. Topograficamente há 3 regiōes: inconsciente, preconsciente e consciente.

- ECONômica - Aquela que se ocupa do movimento de energia dentro do aparelho psíquico, que pode ser investida ou desinvestida das representaçōes mentais. 
DOMINGUES, E F. - Modelagem de Comprrtamento da Gestante Tabagista - Cuidado Preventivo da Enfermagem Obstétrica. Rev. Bras. Enf.; DF, 34 : 153-163, 1981.

\section{7 - ANALISE ETIOPATOGÊNICA}

O desenvolvimento do hábito de fumar na mulher moderna, inclusive durante a gestação, aumentou a possibilidade de incidentes e complicaçōes neste período, como por exemplo: placenta prévia, descolamento prematuro de placenta, pielonefrites. No feto, ocasiona problemas metabólicos e tróficos além de prematuridade, baixo peso, freqüência de severas lesōes cerebrais corigênitas, maior percentagem de akortamentos, mortalidade perinatal e neonatal tardia.

Segundo Rezende 10, "O vício de fumar na gestante aconselha seja a sua prenhez tratada como de alto risco".

As pesquisas realizadas recentemente nos EUA têm enfatizado a gravidade da dependência à nicotina. De acordo com os americanos, fumar cigarros é essencialmente uma forma de administrar nicotina, do mesmo modo, que fumar ópio, é uma forma de administrar morfina 8

Estudos retrospectivos atuais, feitos em diversos países, confirmam plenamente constantaçōes anteriores que põem em relevo a deficiência ponderal e a prematuridade dos recém-nascidos de mães que fumam durante a gravidez.

Tanto a diminuição do peso dos fetos quanto a prematuridade estão correlacionadas ao hábito tabagista, em especial após o $4 .^{\circ}$ mês de gestação e ao número de cigarros fumados diariamente.

Estudos de Chomstock ${ }^{12}$ de $12 \mathrm{mil}$ partos, os prematuros das gestantes fumantes formam 59 por mil e das abstêmias 1,1 por mil o que dá uma diferença de $43 \%$.

Noutro inquérito, por Butler ${ }^{17}$, em 200 mil partos, a freqüência de prematuros foi quase $50 \%$ maior nas gestantes fumantes.
Conforme algumas verificaçōes, o hábito de tragar o fumo torna ainda mais nocivo o efeito para o concepto.

Nos EUA, vários estudos concordam que as mães negras fumantes têm maior indice de prematuros que as mães brancas também tabagistas, variando os percentuais de $12 \%$ a $64 \%$. Essa diferença desfavorável, outrossim, foi notada em relação às gestantes caucasianas. E discutida se as divergências raciais entram em jogo, ou se, nesses casos, se somam as deficiências orgânicas decorrentes de condiçōes econômico-sociais desfavoráveis ${ }^{11}$

\section{8 - MECANISMO DE AÇÃO DO FUMO NA GRAVIDEZ}

A explicação mais plausível do efeito nocivo do fumo sobre o feto é o nível de monóxido de carbono no sangue materno, conseqüentemente na circulação placentária e no feto gerando certo grau de hipóxia. Quanto maior a concentração do $\mathrm{CO}$ no feto, mais o predispōe à hipoxia, pela diminuição da quantidade de hemoglobina livre e disponível para transporte de $\mathrm{O}_{2}$, e pela depressão da anidrase carbônica respiratória (enzima, que cataliza o dióxido de carbono ( $\mathrm{CO}^{2}$ ) nos tecidos e nos pulmōes, libertando-o do sangue).

Decorrente desta hipóxia, advém os prejuízos sobre o feto devido à baixa pressão parcial de oxigênio nos vasos umbilicais, equivalente a $41 \%$ de redução na circulação fetal ou na concentração de hemoglobina dessa circulação ${ }^{5}$.

A hipóxia justifica a prematuridade e em conseqüência a mortalidade perinatal, pois parece incontestável que, diminuindo o peso do feto, o tabagismo constitua risco de vida para o recémnascido.

Paralelamente, invoca-se o efeito da nicotina que atua sobre o sistema circulatório, reduzindo a circulação placentária. Sua ação se faz sobre o sistema 
DOMINGUES, E.F. - Modelagem de Comportamento da Gestante Tabagista - Cuidado Preventivo da Enfermagem Obstétrica. Rev. Bras. Enf.; DF, 34 : 153-163, 1981.

parassimpático, simpático e pela liberaçāo de epinefrina (hormônio da supra-renal). Quando injetada em coelhas, provoca contraçōes uterinas. Sāo abundantes as observações experimentais em fêmeas prenhes, proporcionando fetos de menor peso e maior mortalidade fetal. A absorçāo da nicotina se faz rapidamente, determinando vasoconstriçāo na circulaçāo materna. Conseqüentemente diminui o débito sangüíneo da circulaçāo placentária fetal, com os conseqüentes danos da nutrição do feto. As māes anêmicas têm perigo do aumento deste risco.

A quantidade de nicotina existente em cada cigarro é de 0,5 a $1 \mathrm{mg}$. Fumando e retendo a fumaça na boca, absorvem-se $50 \%$ daquele alcalóide, deglutindo-a, até $80 \% 16$. Ela transita facilmente no leite materno, daí ser contra-indicado o fumo durante a lactaçāo.

Em síntese, conclui-se que a substancial literatura sobre o assunto evidencia de modo indiscutivel e irrefutável os efeitos deletérios sobre o concepto. Por esses motivos, é importante que as māes gestantes se abstenham de fumar.

Estas estimativas nos ajudam a argumentar a validade do intento de modelagem comportamental da gestante tabagista, numa campanha multiplicadora de ações. Significa podermos salvar uma entre cinco ou dez crianças perdidas, se suas māes gestantes se tornem abstêmias.

\section{9 - REVISAO DE LITERATURA}

Partindo-se de um raciocinio lógico, do mesmo modo que as campanhas de trânsito nāo sustam os acidentes, mas servem para reduzi-los, as campanhas contra o fumo se não conseguem erradicar o vício, indubitavelmente dariam oportunidade de opçāo àqueles que. alertados para os perigos, resolvem se resguardar.
Deste princípio advém a hipótese das vantagens de uma modelagem comportamental gradativa, conseguida através de mensagens que, como sementes de edificaçāo e desafio, disseminam bons frutos dessa semeadura.

Segundo a teoria de BERNI \& FORDYCE 1, na análise de problemas em termos comportamentais, o mais adequado é nos determos no objetivo; pois o que se pretende é ajudar o indivíduo a "ser capaz de REALIZAR COISAS mais, ou melhor, do que se nós nāo o assistissemos". Significa que, se o paciente pode realizar mais coisas de modo melhor, ele será mais beneficiado do que se nós fizermos as coisas por ele, deixando-o apenas sentir-se melhor. A interpretação de como é feita a açāo por ele é mais significativa para avaliarmos se estará ou nāo avançando no seu plano terapêutico. Assim, que o programa de modificaçāo de um comportamento deve dirigir-se diretamente ao que o paciente ESTÁ FAZENDO, (à ação).

Quando nós, enfermeiros obstetras, orientamos a gestante para iniciar a fazer algo que ela precisa, estamos pedindo para mudar um COMPORTAMENTO. Nāo para mudar sua motivaçāo ou sua atitude de dependência da enfermagem, apenas para ser agradável ao nosso apelo; mas, sim, para mudar o que ela realmente faz, visando ao seu próprio benefício e do concepto.

Uma das técnicas para o desenvolvimento de um comportamento, ou para a aquisiçāo de um novo, é agir de forma que as conseqüencias imediatas àquele comportamento sejam positivas e possam reforçar a açāo do indivíduo ${ }^{3}$. Acreditamos que a hipótese da paciente abstêmia ter maiores chances de parir filhos sadios e perfeitos, lhe aumentam a segurança, atuando como reforço positivo na mudança comportamental. 
DOMINGUES, E.F. - Modelagem de Comportamento da Gestante Tabagista - Cuidado Preventivo da Enfermagem Obstétrica. Rev. Bras. Enf.; DF, 34 : 153-163, 1981.

\section{0 - METODOLOGIA}

Sabe-se que o comportamento humano pode ser gradativamente modelado através de reforços que, após um determinado tempo, irão influir para : aquisição de um novo comportamento 15.

Baseado neste princípio, tentamos preconizar uma metodologia sistematizada com finalidade preventiva, na qual a enfermagem programa e realiza operaçōes intermediárias ou PASSOS, para atingir o objetivo desejado: redução ou rejeição do vício da grávida tabagista, durante a prenhez. Todavia, para haver efetividade, eficácia e rapidez dos resultados obtidos, o processamento deve obedecer a uma sistematização, para que os reforços atuem como variáveis positivas do novo comportamento adquirido. Quanto mais ligeiro o individuo responder ao apelo, maior número de vezes será reforçado e a aprendizagem será mais veloz.

A gestante orientada não pode ser entendida fora do contexto do sistema geral em que está inserida, externo ac seu eu, formado pelos vários subsistemas (familiar, profissional, comunitário) nem fora da sua própria configuração psicossomática (células, órgãos, aparelhos, sistemas, psiquismo). E essencial que se observe nas ações desta paciente o reflexo do funcionamento orgânico como um todo. Saber o que pensa, o que será capaz de fazer e que potencial especifico tem ela como pessoa.

\section{1 - SISTEMICA DA MODELAGEM}

Após estas investigaçōes, dá-se inicio à operacionalização modધladora, assim delineada:

1.0 Definir o comportamento final. Corresponde ao objetivo desejado que se propōe à paciente atingir.

2. ${ }^{\circ}$ Saber o comportamento inicial mais próximo ao final. Consiste en identificar a predisposição e capacitação de conduta da gestante tabagista, para a ação desejada. Descobrir o que ela conhece em termos gerais correlacionado às razōes da sua modelagem comportamental.

3..$^{\circ}$ Determinar aonde a grávida deverá chegar, programando as operaçōes que serão realizadas como critérios intermediários ou PASSOS, para atingir o objetivo final.

4. ${ }^{\circ}$ Conduzir a gestante através de estimulos externos reforçadores, adequados e constantes.

5. ${ }^{\circ}$ Fomentar a otimização do desempenho pessoal da mesma, na sua privaticidade de modo a conduzi-la a reforços naturais por motivação.

6. ${ }^{\circ}$ Avaliar se o comportamento novo e desejado foi atingido pela gestante, capacitando-a a atuar sozinha quando necessário.

$\mathrm{Na}$ dinâmica por nós utilizada para aquisição do objetivo final, exploramos psicologicamente o instinto maternal, bem como a potencialidade da autodisciplina.

Em tese, partimos de um processo filosófico por meio do qual subimos do composto ao simples, do efeito às causas.

Optamos pelo principio de PREMAK', ou seja, que comportamentos fortes (o que a pessoa faz bastante) parecem ser reforços positivos para aumentar a frequência de comportamentos fracos (o que ela não faz muito).

A nossa técnica consta de atividades desenvolvidas durante os contatos das consultas subseqüentes, com as 58 gestantes listadas, para nossa atuação catequésica. Em cada retorno da paciente, apela-se para a sua potencialidade deliberativa individual, "pontochave" de todo o processo de engrenagem da mudança que se pretende realizar.

No plano elaborado para assistência individual, de acordo com o desempenho de cada tabagista atendida, se esquematiza os reforços progressivos 
DOMINGUES, E.F. - Modelagem de Comportamento da Gestante Tabagista - Cuidado Preventivo da Enfermagem Obstétrica. Rev. Bras. Enf.; DF, 34 : 153-163, 1981.

necessários durante a evolução do processo, quando serão avaliadas as reaçōes que orientarão os novos e consecutivos reforços posteriores.

Isto é, feito sucessivamente, através de operaçōes intermediárias ou PASSOS, até que se possa estabelecer a avaliação da clientela trabalhada. Esta é a última etapa, para se ajuizar o comportamento final, ou seja, a GENERALIZAC̣AO.

\section{2 - Processos Operacionais}

Realizamos atividades comuns a todo trabalho de pesquisa: delineamento de objetivos, o conhecimento das condiçōes disponiveis e a determinação de prioridades.

10.2.1 - Planejamento do Trabalho - Após o levantamento bibliográfico específico, que foi bastante escasso, fizemos contatos com os elementos da equipe Obstétrica da Maternidade Escola da UFBa, onde atuamos na supervisão de alunos, cujo campo escolhemos para universo da nossa amostra populacional.

Foi discutido o plano, por nós elaborado, sobre a campanha a se realizar, e os PASSOS a serem executados, pará cuja realização solicitamos e contamös com o esforço conjugado do grupo.

A nossa idéia, foi aderindo um uúmero cada vez maior de adeptos para cooperar:

O critério para preenchimenio dos questionários pela autora e estudantes, que cursavam na época a disciplina Enfermagem Obstétrica I, foi uniforme e oportuno. Orientamos os alunos, quanto aos detalhes e terminologia do contexto, para aumentar as possibilidades de melhores interpretaçōes dos informes pessoais. Estes seriam muito decisivos na metodologia escolhida para condicionamento individual, subordi. rıando os estímulos dos reforços noste. ricoses.

\subsection{2 - RESULTADOS DAS VARIÁ- VEIS ESTUDADAS}

As 58 gestantes entrevistadas pertencem a um baixo nível sócio-economico.

Nossas conclusōes estatísticas dare. mos a seguir: Relacionada ao consumc médio diário de cigarros: 2 maços, $17,2 \%$; $11 / 2$ maço, 20,7\%; 1 maço, 31,0\%; $1 / 2$ maço, $20,7 \%$; variável $10,4 \%$.

Evidenciamos uma predominância de $96,5 \%$ na freqüência do cigarro, sobre o cachimbo $3,5 \%$. O hábito de tragar atinge a um total de $70 \%$, apenas $30 \%$ não absorve a fumaça.

Quanto às razôes que as levam a fumar - 29,3\% referem-se à dependência; $22,4 \%$, distração; $19,0 \%$, charme; $24,1 \%$, prazer; e 5,2 , outros.

Nossas observaçōes revelaram que, tanto a idade, o estado civil, bem como a procedência não têm analogia com as perguntas incluidas no questionário: Conhece os efeitos nocivos do fumo para a saúde em geral? E particularmente sobre a gravidez? Entretanto, o nível de escolaridade e ocupação mo:straram relaçōes esclarecedoras quanto às questōes abordadas.

Referente às fontes informativas du:i perigos do vício e necessidade de supressão do hábito tabagista durante a gravidez, por serem incompativeis, concluimos: escola, $22,4 \%$; serviços médicos, $24,1 \%$; pré-natal, $25,9 \%$; imprensa, $22,4 \%$; e outros $5,2 \%$.

Um número considerável de gesiante informa proibição na fase de :ngresso ao vicio de fumar: os pais, $43,1 \%$; criadores, $37,9 \%$; professores, $13,8 \%$ e outros, $5,2 \%$. Comprovaram-se as desvantagens de atuaçōes proibitivas. E:? regra, ao invés de uma educação cle base, no sentido de esclarecer os prejuízos causados pelo fumo à saúde, os superiores hierárquicos se restringem. na maioria, a atividades repressivas e violentas, que surtem efeitos opostos. $\mathrm{O}$ 
DOMINGUES, E.F. - Modelagem de Comportamento da Gestante Tabagista - Cuidado Preventivo da Enfermagem Obstétrica. Rev. Bras. Enf.; DF, 34 : 153-163, 1981.

valor da campanha antifumo consiste em orientar corretamente os jovens masculinos e femininos na fase escolar, através de conteúdos programáticos de incentivos oportunos, regulares e otimistas, dirigidos à juventude.

Relativo à classificação dos comportamentos intermediários tivemos as respostas positivas em número maior $44,8 \%$; as negativas, $24,2 \%$; e as neutras, $31,0 \%$.

\subsection{3 - AVALIAÇÃO}

Ajuizaremos a nossa pesquisa, apenas como um procedimento intermediário e não final; pois consideramos a validade de continuação da mesma. Não obstante, tentamos medir o êxito ou o fracasso até o momento, para facilitar o prosseguir.

Ao assumirmos o desafio de provocar, a curto prazo, uma mudança de comportamento no grupo mais imediatamente afetado pelo fumo, lançamos mãos de todos os enfoques de consistência eventual quanto às atividades relacionadas ao objeto, mas também em relação à situação ambiental. Conseguimos o apoio total, por parte da equipe pré-natalista, com mensagens educativas regulares uniformes. Cada paciente, com sua vontade interior constantemente incentivada, dos pontos de vista físico, social e psicológico, se beneficiou bastante. Por isto, consideramos múltiplos valores aquisitivos, mesmo com mudanças comportamentais pequenas ocorridas, que serão úteis no momento e terão valor cumulativo a favor dos fetos.

\section{1 - CONCLUSŌES}

A propaganda bem elaborada aumenta cada vez mais o número de adeptos do fumo, encontrando eco principal na mulher, impressionada pelas imagens de charme e elegância, conferidas pela publicidade.
As gestantes não podem fugir a esta regra de influência generalizada e competitiva.

Sendo a fase gestacional incompatível com o hábito tabagista, justificase o seu combate, com todo o realismo, que a saúde da grávida e a responsabilidade do enfermeiro exigem.

O objeto deste estudo consiste em abordar aspectos comportamentais que levam à abolição ou redução da quantidade de tabaco infundida à circulação sangüinea fetal. Ele não tem a pretensão de uma análise global; mas, sim, de abrir terreno para reflexão, debates e indagaçōes sobre uma realidade desafiadora que requer a continuidade de programas dessa natureza, por outros profissionais.

Se isto ocorrer, teremos vários benefícios; efeito multiplicador, de campanhas enfatizantes da gravidez nociva da droga; conscientização dos perigos para a gravidez; e maiores chances para que o ovo prossiga o seu desenvolvimento sem esta causa que serve para conturbá-lo.

\section{2 - SUGESTŐES}

Complementando a nossa tarefa, sugerimos que:

- Todos os profissionais pré-natalistas promovam campanhas idênticas, concomitantes às suas atuaçōes de rotina, num trabalho cooperativo, com vistas a legitimar a informação transmitida.

- Os líderes e pessoas representativas do setor de saúde divulguem de maneira regular e uniforme campanhas educativas e profiláticas de repressão ao fumo, em caráter coletivo, através da imprensa falada, escrita e televisada. Com os excelentes veículos de comunicação e divulgação de que dispōem, podem produzir efeitos supressivos e amortecedores das propagandas aliciantes, que fazem as indústrias do tabaco. 
JOMINGUES, E.F. - Modelagem de Comportamento da Gestante Tabagista - Cuidado Preventivo da Enfermagem Obstétrica. Rev. Bras. Enf.; DF, 34 : 153-163, 1981.

- As entidades competentes impeçam as propagandas fascinantes, bem elaboradas, levadas ao público, que in:pressionam a juventude pelas imagens de virilidade, charme e elegân:ìi, corteridas pela publicidade ao ato de fumar.

- As autoridades governamentais, a exemplo da França, exijam que os impostos arrecadados através das in lús.trias de fumo sejam devolvidos, em prestação de assistência médica, às pessoas prejudicadas pelo uso do mesmo. Consta-nos que em São Paulo a renda coletada pelo Estado nas indústrias de fumo já tem esta aplicação.

- Nossa experiência sirva de estímulo a todo profissional militante ra Enfermagem Obstétrica, para se questionar sobre a objetividade e validade de sua própria prática, com atuaçjes detectáveis do vício; que afeta a díada materno-fetal.

\section{3 - RESUMO}

A autora tece consideraçōes sobre tabagismo e sua nocividade para o prognóstico obstétrico. Analisa como o comportamento humano pode ser gradativamente modelado, através de reforços positivos, que, após um determinado tempo, originam a instalação de um novo comportamento. Baseada neste princípio, preconiza uma metodologia sistematizada, com finalidade preventiva, na qual a enfermagem programa e realiza operaçōes intermediárias (PASSOS), para atingir o objetivo desejado; redução ou rejeição ao vício tabagista, durante a gravidez.

A operacionalização consta de estímulos reforçadores e constantes, que atuam como variáveis positivas do comportamento adquirido.

A avaliação progressiva e efetiva da mudança é feita quando se consegue conduzir a paciente a REFORÇOS NATURAIS, motivados pela satisfação pessoal, como uma resposta às suas necessidades.

\section{SUMARY}

The authors make considerations on the effect of smoking on the outcome of pregnancy.

They analyse human behaviour and the reasons for the tabagism. It is emphasized that an ordely methodology will prevent the excessive use or abuse of smoking during pregnancy.

This programme consists of an attempt to give a positive influence upon the patient. The progressive evaluation and the effective changes are accomphlished by making the patient pursue the natural efforts wich are motived by personal satisfation, as an answer to their needs.

\section{B I B L I O G R A F I A}

1. BERNI, R. \& FORDYCE, W. E. Behavior modification and the nursing process. Saint Louis, Mosby, 1973.

2. FREUD, A. - Psicanálise para pedagogos. 5. ed., São Paulo, Martins Fontes, 1971.

3. FUX, M. D. - Experiência de vida y educación. Buenos Aires Paidóes, 1976.

4. HORTA, W. A. - Enfermagem: teoria, conceitos, princípios e processos. $R$.
Escola de Enfermagem da U.S.P., 8 (1) : 7-15, 1974.

5. LEIRZKE, G.: O tabaco e a mulher. Efeitos sobre o organismo feminino e o seu concepto. J: Bras. Med., 24: 18, 1973.

6. LOFREDI, L. E. - Aconselhamento psico-pedagógico fundamentos para $a$ açāo do orientador educacional, I. Encontro preparatório da Gb. Congresso da Asssociação de Orientadores Educacionais - Gb., 1972. 
DOMINGUES, E.F. - Modelagem de Comportamento da Gestante Tabagista - Cuidado Preventivo da Enfermagem Obstétrica. Rev. Bras. Enf.; DF, 34 : 153-163, 1981.

7. MIRA Y LOPES, E. Psicologia Geral. 4. ed., São Paulo, Melhoramentos, 1970.

8. NICOTINA; uma droga poderosa que vicia. Atual. Méd., 15 (1) 17-22, abr., 1979.

9. NOVAES, M. H. - Psicologia aplicada d reabilitação. Rio de Janeiro, Imago, 1975 .

10. REZENDE, J. Efeitos iatrogênicos indesejáveis e farmaco-dependência no ciclo gestatário. Intoxicaçōes. Infortunística. In: - Obstetrícia. 3. ed. Rio de Janeiro, Guanabara Koogan, 1974, págs. 441-2.

11. ROSEMBERG, J. - Tabagismo e sua nocividade para a saúde. 4 - Açāo sobre o coração e circulação periférica. J. Bras. Méd. 34 (3): 45-56, mar. 1978.

12. judiciais na gravidez e na crianç
J. Bras. Méd., 34 (4): 77-85, abr. 1978.

13. RUSK, H. A. - Medicina de rehabilitación. México, Interamericana, 1972.

14. SALZBERGER - WITTENBERG, I. - Psicanálise e serviço social. Río de Janeiro, Imago, 1974.

15. STATS, A. W. \& STATS, C. K. - Comportamento humano complexo. S.P., EPU., pág. 85-94.

16. TANESE, F. R. Passagem transplacentária de drogas. In: PEIXOTO, S. Prénatal, 2. ed., São Paulo, Manole, 1979, págs. 197-206.

17. U.S. DEPARTMENT OF HEALTH EDUCATION, AND WELFARE. Datos sobre el hábito de fumar y la salud. Washington, 1970. 12 págs. (Public Health Service Publ., n. 1712-5). 